\title{
PELAKU MOBILITAS HARIAN PENDUDUK KELUAR KOTA PADANG LEWAT JALUR UTARA
}

\author{
Amelia Sucia Rahmi ${ }^{1}$, Endah Purwaningsih ${ }^{2}$ \\ Program Studi Geografi \\ Fakultas Ilmu Sosial Universitas Negeri Padang \\ Email: mellasuciarahmi@gmail.com
}

\begin{abstract}
Abstrak
Penelitian ini bertujuan untuk mengetahui: 1) Karakteristik pelaku mobilitas harian Kota Padang yang melewati jalur utara menggunakan bus dan kereta api. 2) Arah dan arus mobilitas harian. 3) Kontribusi mobilitas harian terhadap pendapatan pelaku mobilitas. 4) Alasan pelaku mobilitas melakukan mobilitas harian. Jenis penelitian ini deskriptif kuantilatif. Sampel penelitian ditarik secara accidental sampling. Data penelitian dikumpulkan melalui wawancara terstruktur. Penelitian ini menemukan: 1) karakteristik pelaku mobilitas didominasi pelaku mobilitas yang berjenis kelamin perempuan(58\%) dengan umur didominasi antara 35-48 tahun(41\%). Status pernikahan didominasi sudah menikah(79\%), dengan tingkat pendidikan didominasi lulusan S1(61\%). 2) Kontribusi terhadap pendapatan pelaku mobilitas adalah meningkatnya pendapatan pelaku mobilitas setelah melakukan mobilitas harian yakni dengan pendapatan antara Rp 1.500.000-6.000.000/bulan dengan pekerjaan didominasi Pegawai Negeri Sipil(54\%). 3) Alasan pelaku mobilitas melakukan mobilitas harian karena keluarga tinggal di Padang dan jarak yang dekat antara tempat tinggal dengan daerah tujuan, alasan ini didukung oleh arah tujuan mobilitas harian yang didominasi ke Padang Pariaman dan Kota Pariaman.
\end{abstract}

Kata kunci: mobilitas harian, karakteristik pelaku mobilitas, arah dan tujuan mobilitas

\begin{abstract}
This research has purpose to know: 1) characteristic the migrant of commuting Padang city passing north path using bus and train 2) direction and flow of commuting out of Padang city 3) the contribution commuting to mobility revenue 4) the reasons mobility for commuting and the reasons for commuting is by bus and train. Type of research is descriptive quantitatif and quantilatif. Sampling by accidental sampling. This research data collected through structured interviews. The study found: 1) the characteristic of the migrant is dominated by women(58\%) aged is dominated between 35-48 years (41\%). Dominate is married (79\%), with a predominantly S1(61\%). 2) Contribution to income is the increasing mobility of mobility after commuting with intermediate income Rp 1.500.000-6.000.000/month with government employees job(54\%). 4) The reason for mobility because families living in Padang and close distance between residence and destination area, this reason is supported by the direction of daily mobility destination dominated to Padang Pariaman and Pariaman city.
\end{abstract}

Keywords: commuting, characteristic the migrant of mobility, direction and purpose of mobility 


\section{PENDAHULUAN}

Istilah mobilitas penduduk menurut Mantra (2009:172) dibedakan menjadi mobilitas penduduk vertikal dan mobilitas horizontal. Mobilitas penduduk vertikal sering disebut dengan perubahan status. Mobilitas horizontal atau mobilitas penduduk geografis, adalah gerak (movement) penduduk yang melintas batas wilayah menuju wilayah lain dalam periode waktu tertentu (Mantra, 1978).

Peningkatan sarana transportasi, komunikasi dan kemajuan teknologi prasarana jalan serta pembangunan regional juga berpengaruh pada volume dan arahan mobilitas penduduk yang membuat jarak antar daerah relatif makin pendek dan lancar, maka akan semakin besar pula arus mobilitasnya. Dengan membaiknya sarana transportasi ini, maka frekuensi mobilitas non permanen meningkat dan frekuensi mobilitas permanen menurun. Sehingga menyebabkan tenaga kerja akan mencari pekerjaan di wilayah manapun selama di wilayah tersebut dia mendapatkan upah yang lebih tinggi.

Kota Padang merupakan ibukota dari Provinsi Sumatera Barat, yang terletak di pantai barat Pulau Sumatera, dengan luas keseluruhan Kota Padang yaitu $694,96 \mathrm{~km}^{2}$ atau setara dengan 1,6 $\%$ luas Provinsi Sumatera Barat. Kota Padang merupakan kota dengan jumlah penduduk paling banyak di Provinsi Sumatera Barat. Ditinjau dari data BPS, penduduk usia 15 tahun keatas yang bekerja, persentase pengangguran, dan partisipasi angkatan kerja menurut kabupaten/kota selama periode Agustus 2013 - Agustus 2014 Provinsi Sumatera
Barat, TPT (Tingkat Pengangguran Terbuka) dari 10 kabupaten/kota mengalami kenaikan dan 9 kabupaten/kota mengalami penurunan. Pada Agustus 2014 TPT di Kota Padang masih berada pada level tertinggi yakni sebesar 12,28 persen turun sebesar 1,82 persen dibandingkan kondisi Agustus 2013 yaitu 14,10 persen. Sementara itu, TPT terendah terdapat di Kabupaten Kepulauan Mentawai yaitu sebesar 1,66 persen (BPS Provinsi Sumatera Barat). Berdasarkan data diatas dapat diketahui bahwa Kota Padang merupakan Kota yang memiliki TPT (Tingkat Pengangguran Terbuka) tertinggi dibandingkan kota atau kabupaten lainnya di Provinsi Sumatera Barat, itu disebabkan karena jumlah penduduk dan kepadatan penduduk yang tinggi di Kota Padang yang tidak diiringi dengan bertambahnya lapangan pekerjaan di Kota Padang.

Ditinjau dari pergerakan penduduk keluar Kota Padang, baik itu permanen ataupun nonpermanen seperti mobilitas harian (ulang alik), Kota Padang itu sendiri memiliki 3 akses atau 3 jalur keluar dari Kota Padang, yakninya di arah Selatan Kota Padang yang merupakan jalur keluar dari Kota Padang menuju Kabupaten Pesisir Selatan. Di arah Timur, merupakan gerbang keluar dari Kota Padang untuk menuju daerah Kabupaten Solok, Kota Solok, Kabupaten Solok Selatan, Kota Sawahlunto, dan Kabupaten Sijunjung. Sedangkan untuk arah utara yang merupakan jalur keluar dari Kota Padang menuju Kabupaten Padang Pariaman, Kota Pariaman, Kota Padang Panjang, Kota Bukittinggi, Kabupaten 
Tanah Datar, Kabupaten Agam, Kabupaten Lima Puluh Kota, Kota Payakumbuh, Kabupaten Pasaman Barat, dan Kabupaten Pasaman. Berdasarkan penjelasan di atas, maka peneliti ingin meneliti tentang "Pelaku Mobilitas Harian Penduduk Keluar Kota Padang Lewat Jalur Utara”. Peneliti mengambil akses atau jalur utara karena daerah tujuan untuk bagian utara itu termasuk banyak dibandingkan 2 gerbang keluar Kota Padang lainnya, dan juga ada beberapa daerah tujuannya yang merupakan pusat sentral perekonomian masyarakat seperti Kota Bukittinggi.

Menurut Peraturan Presiden Republik Indonesia No. 153 Tahun 2014, mobilitas penduduk diartikan sebagai gerak keruangan penduduk dengan melewati batas administrasi pemerintahan. Mobilitas penduduk dapat dilihat dalam artian fisik yaitu perpindahan penduduk untuk memperoleh peluang kesempatan yang lebih luas di tempat lain (mobilitas horizontal), dan dalam arti sosial, ekonomi, dan budaya yaitu upaya peningkatan status melalui peningkatan kesejahteraan (mobilitas vertikal).

Mobilitas penduduk juga dapat dilihat dari batasan waktu yaitu mobilitas permanen dan non permanen. Sementara itu mobilitas non permanen dapat dibedakan lagi menjadi mobilitas ulang alik (commuter) dan nginap. Menurut Suasti (2013: 141), mondok merupakan mobilitas penduduk yang melewati batas teritorial dalam masa kurang dari enam bulan atau lebih dari enam bulan tetapi tidak untuk menetap. Menurut Mantra (2009: 174), mobilitas ulang alik adalah gerak penduduk dari daerah asal menuju ke daerah tujuan dalam batas waktu tertentu dan kembali ke daerah asal pada hari itu juga. Mobilitas ulang alik waktunya diukur dengan enam jam atau lebih meninggalkan daerah asal dan kembali pada hari yang sama.

Menurut Sri (2010) faktor pendorong seseorang meninggalkan tempat lamanya adalah semakin berkurang sumber-sumber kehidupan, menyempitnya lapangan pekerjaan di tempat asal, adanya tekanan-tekanan atau diskriminasi politik, agama, dan suku sehingga mengganggu hak asasi penduduk di daerah asal, tidak cocok lagi dengan adat/budaya/kepercayaan di tempat asal, alasan pekerjaan atau perkawinan, bencana alam. Sedangkan faktor-faktor penarik adalah: adanya rasa superior di tempat yang baru atau kesempatan untuk memasuki lapangan pekerjaan yang cocok, kesempatan memperoleh pendapatan yang lebih baik, kesempatan untuk memperoleh pendidikan yang lebih tinggi, keadaan lingkungan dan keadaan hidup yang menyenangkan, tarikan dari orang yang diharapkan sebagai tempat berlindung, dan adanya aktivitas-aktivitas di kota besar, tempat hiburan, atau pusat kebudayaan yang merupakan daya tarik bagi orang-orang daerah lain untuk bermukim di kota besar.

Terkait dengan lokasi maka salah satu faktor yang menentukan apakah suatu lokasi menarik untuk dikunjungi atau tidak adalah tingkat aksesibilitas. Tarigan (2005:140) menyebutkan aksesibilitas adalah kemudahan mencapai kota atau wilayah lain yang 
berdekatan bagi masyarakat yang ada di suatu kota. Menurut Tarigan, tingkat aksesibilitas dipengaruhi oleh jarak, kondisi prasarana perhubungan, ketersediaan berbagai frekuensinya dan tingkat keamanan serta kenyamanan untuk melalui jalan tersebut.

Prasarana transportasi di Indonesia telah dibangun dengan baik. Jalan-jalan yang menghubungkan wilayah satu dengan wilayah lain telah dan sedang dibangun (bagi yang belum ada) dan bagi yang sudah ada ditingkatkan kualitasnya. Jalan-jalan diperlebar dan diperkeras dengan aspal. Peningkatan prasarana jalan diikuti pula oleh pengadaan kendaraan umum yang mengikuti rute-rute terpencil. Membaiknya prasarana transportasi ini maka frekuensi mobilitas non permanen meningkat dan frekuensi mobilitas permanen menurun. Jadi dapat dikatakan bahwa aksesibilitas merefleksikan jarak pemindahan diantara beberapa tempat yang dapat diukur dengan waktu dan biaya yang dibutuhkan untuk perpindahan tersebut.

\section{METODE PENELITIAN}

Jenis penelitian ini adalah penelitian deskriptif kuantilatif (gabungan kualitatif dan kuantitatif). Subjek penelitian ini adalah penduduk Kota Padang yang melakukan mobilitas harian keluar Kota Padang yang melewati jalur utara, dan menggunakan angkutan umum antar kota (bus dan kereta api). Pada penelitian ini, sampel yang digunakan adalah accidental sampling.

Lokasi penelitian yang adalah di titik-titik terminal bayangan bus angkutan antar kota yang keluar dari Kota Padang di sepanjang Jalan Prof. Dr. Hamka. Titik terminal bayangan yang dijadikan tempat penelitian adalah di Ulak Karang (depan kantor DPRD), depan basko, depan UNP, simpang Cendrawasih, dekat Stasiun Tabing. Sedangkan untuk stasiun kereta api dilakukan di empat titik yakni di Stasiun Simpang Haru, Stasiun Air Tawar (dekat Basko), Stasiun Tabing, dan Stasiun Lubuk Buaya.Waktu penelitian dilaksanakan pada hari senin- jumat pada bulan Januari - Februari 2017. Wawancara dilakukan pada pagi hari yakni dimulai dari pukul 05.00 WIB sampai pukul 08.00 WIB.

Jenis data yang digunakan adalah data primer. Data primer yang dibutuhkan dalam penelitian ini adalah: 1) Data krakteristik pelaku mobilitas harian meliputi jenis kelamin, umur, status perkawinan, tingkat pendidikan, jenis pekerjaan, dan pendapatan ratarata pelaku mobilitas harian. 2) data arah dan arus tujuan pelaku mobilitas harian. 3) kontribusi mobilitas harian terhadap pendapatan pelaku mobilitas harian. 4) motivasi dan alasan pelaku mobilitas melakukan mobilitas harian yang didapatkan dari wawancara langsung dengan pelaku mobilitas. Sesuai dengan alat pengumpul data yang berbentuk daftar pertanyaan wawancara, cara yang digunakan dalam penelitian ini adalah wawancara dan dokumentasi.

Teknik analisis data yang digunakan dalam metode analisis data kuantitatif adalah teknik persentase, untuk mengolah data akhir, digunakan 
rumus statistik deskriptif berikut dengan formula:

$$
\mathrm{P}=\frac{f}{N} \mathrm{x} 100 \% \text { (Martono, 2010: }
$$

Metode analisis data kualitatif dilakukan melalui beberapa tahap analisis data menurut Millies dan A Hubberman (1984) dalam Sugiyono (2005:91) adalah reduksi data, penyajian data dan pengambilan kesimpulan.
HASIL DAN PEMBAHASAN

1. Karakteristik Pelaku Mobilitas

\section{Harian}

a. Jenis Kelamin

Hasil penelitian yang didapatkan dari penelitian di lapangan, dapat diketahui sebagian besar responden yang melakukan mobilitas harian keluar Kota Padang didominasi oleh pelaku mobilitas yang berjenis kelamin perempuan, seperti yang terlihat pada tabel di bawah ini:

Tabel 1: Jenis Kelamin Pelaku Mobilitas Harian

\begin{tabular}{|c|c|c|c|c|c|c|c|c|c|}
\hline \multirow[t]{3}{*}{ No } & \multirow{3}{*}{$\begin{array}{c}\text { Jenis } \\
\text { Kelamin }\end{array}$} & \multirow{2}{*}{\multicolumn{2}{|c|}{ Bus }} & \multicolumn{4}{|c|}{ Pariaman } & \multirow{2}{*}{\multicolumn{2}{|c|}{ Jumlah }} \\
\hline & & & & \multicolumn{2}{|c|}{ Bus } & \multicolumn{2}{|c|}{$\begin{array}{c}\text { Kereta } \\
\text { api }\end{array}$} & & \\
\hline & & $\mathbf{F}$ & $\%$ & $\mathbf{f}$ & $\%$ & $\mathbf{f}$ & $\%$ & f & $\%$ \\
\hline 1 & Laki-laki & 27 & 34 & 1 & 1 & 6 & 7 & & \\
\hline 2 & Perempuan & 30 & 37 & 2 & 3 & 14 & 18 & & \\
\hline & Jumlah & 57 & 71 & 3 & 4 & 20 & 25 & 80 & 100 \\
\hline
\end{tabular}

Sumber: Pengolahan Data Primer 2017

Berdasarkan tabel di atas dapat disimpulkan bahwa jumlah pelaku mobilitas harian yang keluar Kota Padang didominasi oleh pelaku mobilitas yang berjenis kelamin perempuan dengan jumlah 46 orang atau dengan persentase $57 \%$ dan berjenis kelamin laki-laki sebanyak 34 orang dengan persentase $43 \%$.

b. Umur

Umur atau usia adalah satuan waktu yang mengukur waktu keberadaan suatu benda atau makhluk, baik yang hidup maupun yang mati, dimana umur sangat mempengaruhi stamina seseorang, karena semakin tua seseorang maka stamina nya berkurang dan makin kecil. Umur pelaku mobilitas harian yang didapat dari hasil wawancara terhadap 80 responden tersebut dapat dilihat pada tabel di bawah ini :

Tabel 2: Umur Pelaku Mobilitas Harian

\begin{tabular}{|c|c|c|c|c|c|c|c|c|c|}
\hline \multirow{3}{*}{$\begin{array}{l}\text { No } \\
\text {. }\end{array}$} & \multirow[t]{3}{*}{ Umur } & \multirow{2}{*}{\multicolumn{2}{|c|}{ Bus }} & \multicolumn{4}{|c|}{ Pariaman } & \multirow{2}{*}{\multicolumn{2}{|c|}{ Jumlah }} \\
\hline & & & & \multicolumn{2}{|c|}{ Bus } & \multicolumn{2}{|c|}{ Kereta api } & & \\
\hline & & $\mathbf{F}$ & $\%$ & f & $\%$ & $\mathbf{F}$ & $\%$ & \multirow[t]{4}{*}{$\mathbf{f}$} & \multirow[t]{4}{*}{$\%$} \\
\hline 1 & $21-34$ & 18 & 22 & 0 & 0 & 9 & 11 & & \\
\hline 2 & $35-48$ & 23 & 29 & 2 & 3 & 8 & 10 & & \\
\hline 3. & $49-62$ & 16 & 20 & 1 & 1 & 3 & 4 & & \\
\hline \multicolumn{2}{|c|}{ Jumlah } & 57 & 71 & 3 & 4 & 20 & 25 & 80 & 100 \\
\hline
\end{tabular}

Sumber: Pengolahan Data Primer 2017 
Berdasarkan tabel di atas dapat diketahui umur responden yang melakukan mobilitas harian keluar Kota Padang bervariasi. Dilihat dari umur pelaku mobilitas penduduk yang keluar Kota Padang pada jalur utara memperlihatkan bahwa yang terbanyak adalah pada umur 21-34 dan 35-48 tahun, masing-masing $34 \%$ dan $41 \%$, sedangkan sisanya adalah pelaku mobilitas yang berumur 49-62 tahun. c. Status Perkawinan

Status dari responden yang merupakan pelaku mobilitas harian keluar Kota Padang ini beragam yakni ada yang sudah menikah dan ada yang belum menikah. Status perkawinan pelaku mobilitas harian keluar Kota Padang dapat dilihat pada tabel di bawah ini :

\section{Tabel 3: Status Perkawinan Pelaku Mobilitas Harian}

\begin{tabular}{|c|c|c|c|c|c|c|c|c|c|}
\hline \multirow{3}{*}{$\begin{array}{l}\mathbf{N} \\
\text { o. }\end{array}$} & \multirow{3}{*}{$\begin{array}{c}\text { Status } \\
\text { Perkawinan }\end{array}$} & \multirow{2}{*}{\multicolumn{2}{|c|}{ Bus }} & \multicolumn{4}{|c|}{ Pariaman } & \multirow{2}{*}{\multicolumn{2}{|c|}{ Jumlah }} \\
\hline & & & & \multicolumn{2}{|c|}{ Bus } & \multicolumn{2}{|c|}{$\begin{array}{c}\text { Kereta } \\
\text { api }\end{array}$} & & \\
\hline & & f & $\%$ & $\mathbf{f}$ & $\%$ & $\mathbf{f}$ & $\%$ & \multirow[t]{3}{*}{$\mathbf{f}$} & \multirow[t]{3}{*}{$\%$} \\
\hline 1 & Nikah & 49 & 61 & 2 & 3 & 12 & 15 & & \\
\hline 2 & Belum Nikah & 8 & 10 & 1 & 1 & 8 & 10 & & \\
\hline & Jumlah & 57 & 71 & 3 & 4 & 20 & 25 & 80 & 100 \\
\hline
\end{tabular}

Sumber: Pengolahan Data Primer 2017

Berdasarkan tabel di atas dapat diketahui bahwa pada umumnya pelaku mobilitas harian sudah menikah baik yang naik bus maupun kereta api. Jumlah pelaku mobilitas harian yang sudah menikah adalah sebanyak 63 atau $79 \%$ orang dan 17 orang atau $21 \%$ dengan status belum nikah.

\section{d. Tingkat Pendidikan}

Pendidikan berpengaruh terhadap seseorang dalam melakukan mobilitas untuk mencari pekerjaan dan kehidupan yang lebih baik, dapat dilihat pada tabel dibawah ini tingkat pendidikan pelaku mobilitas harian:

Tabel 4: Tingkat Pendidikan Pelaku Mobilitas Harian

\begin{tabular}{|c|c|c|c|c|c|c|c|c|c|}
\hline \multirow{3}{*}{$\begin{array}{l}\mathbf{N} \\
\text { o. }\end{array}$} & \multirow{3}{*}{$\begin{array}{c}\text { Pendidika } \\
n\end{array}$} & & \multicolumn{4}{|c|}{ Pariaman } & \multirow{2}{*}{\multicolumn{2}{|c|}{ Jumlah }} \\
\hline & & & & \multicolumn{2}{|c|}{ Bus } & \multicolumn{2}{|c|}{$\begin{array}{c}\text { Kereta } \\
\text { api }\end{array}$} & & \\
\hline & & f & $\%$ & $\mathbf{f}$ & $\%$ & $\mathbf{f}$ & $\%$ & \multirow[t]{6}{*}{$\mathbf{f}$} & \multirow[t]{6}{*}{$\%$} \\
\hline 1 & SMP & 5 & 6 & 0 & 0 & 3 & 4 & & \\
\hline 2 & SMA & 8 & 10 & 0 & 0 & 5 & 6 & & \\
\hline 3 & D3 & 2 & 3 & 0 & 0 & 2 & 10 & & \\
\hline 4 & S1 & 36 & 45 & 3 & 4 & 10 & 12 & & \\
\hline 5 & S2 & 6 & 7 & 0 & 0 & 0 & 0 & & \\
\hline & Jumlah & 57 & 71 & 3 & 4 & 20 & 25 & 80 & 100 \\
\hline
\end{tabular}

Sumber: Pengolahan Data Primer 2017

Pelaku mobilitas harian yang melakukan mobilitas harian keluar Kota
Padang didominasi oleh pelaku mobilitas yang pendidikan akhirnya S1 
dengan jumlah 49 orang atau sebesar $61 \%$, tingkat pendidikan SMA sebanyak 13 orang atau sebesar $16 \%$, tingkat pendidikan S2 sebanyak 6 orang atau sebesar $8 \%$, tingkat pendidikan SMP sebanyak 8 orang atau sebesar $10 \%$, dan yang terakhir pendidikan akhir D3 sebanyak 4 orang atau sebesar $5 \%$. e. Jenis Pekerjaan

Jenis pekerjaan 80 responden yang diwawancarai di lapangan beraneka ragam. Untuk lebih jelas jenis pekerjaan pelaku mobilitas harian keluar Kota Padang dapat dilihat pada tabel dibawah ini:

Tabel 5: Jenis Pekerjaan Pelaku Mobilitas Harian

\begin{tabular}{|c|c|c|c|c|c|c|c|c|c|}
\hline \multirow[t]{3}{*}{ No } & \multirow[t]{3}{*}{ Pendidikan } & \multirow{2}{*}{\multicolumn{2}{|c|}{ Bus }} & \multicolumn{4}{|c|}{ Pariaman } & \multirow{2}{*}{\multicolumn{2}{|c|}{ Jumlah }} \\
\hline & & & & \multicolumn{2}{|c|}{ Bus } & \multicolumn{2}{|c|}{ Kereta api } & & \\
\hline & & $\mathbf{f}$ & $\%$ & $\mathbf{f}$ & $\%$ & f & $\%$ & \multirow[t]{8}{*}{$\mathbf{f}$} & \multirow[t]{8}{*}{$\%$} \\
\hline \multirow[t]{4}{*}{1} & PNS & & & & & & & & \\
\hline & - Guru & 17 & 21 & 2 & 3 & 6 & 7 & & \\
\hline & - Peg. Kantor & 9 & 11 & 1 & 1 & 2 & 3 & & \\
\hline & - Dosen & 6 & 8 & 0 & 0 & 0 & 0 & & \\
\hline 2. & Pedagang & 8 & 10 & 0 & 0 & 5 & 6 & & \\
\hline 3. & Wiraswasta & 4 & 5 & 0 & 0 & 2 & 3 & & \\
\hline 4. & Peg. Swasta & 13 & 16 & 0 & 0 & 5 & 6 & & \\
\hline \multicolumn{2}{|r|}{ Jumlah } & 57 & 71 & 3 & 4 & 20 & 25 & 80 & 100 \\
\hline
\end{tabular}

Sumber: Data Primer tahun 2017

Jenis pekerjaan pelaku mobilitas harian didominasi oleh pekerjaan sebagai guru dengan jumlah 25 orang atau sebesar 32\%, lalu diikuti oleh pegawai swasta dengan jumlah responden sebanyak 18 orang atau sebesar 23\%. Selanjutnya pekerjaan pelaku mobilitas sebagai pegawai kantor memiliki jumlah sebanyak 12 orang atau sebesar $15 \%$. Jenis pekerjaan selanjutnya adalah pedagang dengan jumlah responden sebanyak 13 orang atau sebesar $16 \%$, lalu diikuti oleh jenis pekerjaan sebagai dosen dan wiraswasta yang memiliki jumlah yang sama yaitu sebesar 6 orang atau $7 \%$.

f. Pendapatan rata-rata

Pendapatan rata-rata pelaku mobilitas harian penduduk keluar Kota Padang juga beraneka ragam, seperti yang terlihat pada tabel di bawah ini :

Tabel 6: Pendapatan Rata-rata Pelaku Mobilitas Harian

\begin{tabular}{|c|c|c|c|c|c|c|c|c|c|}
\hline \multirow[t]{3}{*}{ No } & \multirow[t]{3}{*}{ Pendapatan (Rp) } & \multirow{2}{*}{\multicolumn{2}{|c|}{ Bus }} & \multicolumn{4}{|c|}{ Pariaman } & \multirow{2}{*}{\multicolumn{2}{|c|}{ Jumlah }} \\
\hline & & & & \multicolumn{2}{|c|}{ Bus } & \multicolumn{2}{|c|}{ Kereta api } & & \\
\hline & & $\mathbf{f}$ & $\%$ & $\mathbf{f}$ & $\%$ & $\mathbf{f}$ & $\%$ & \multirow[t]{4}{*}{$\mathbf{f}$} & \multirow[t]{4}{*}{$\%$} \\
\hline 1 & $1.500 .000-3.000 .000$ & 20 & 25 & 3 & 4 & 17 & 21 & & \\
\hline 2 & $3.100 .000-4.500 .000$ & 21 & 26 & 0 & 0 & 3 & 4 & & \\
\hline 3 & $4.600 .000-6.000 .000$ & 16 & 20 & 0 & 0 & 0 & 0 & & \\
\hline & Jumlah & 57 & 71 & 3 & 4 & 20 & 25 & 80 & 100 \\
\hline
\end{tabular}

Sumber: Pengolahan Data Primer 2017 
Dari 80 pelaku mobilitas harian yang pendapatan sebesar Rp 1.500.000 - Rp 3.000.000 merupakan pendapatan paling banyakyang didapatkan oleh pelaku mobilitas harian yakni sebanyak 40 orang atau sebesar $50 \%$, diikuti dengan pendapatan sebesar $\mathrm{Rp}$ 3.100.000 - 4.500.000 dengan jumlah sebanyak 24 orang responden atau sebesar 30\%, dan pendapatan $\mathrm{Rp}$ 4.600 .000 - 6.000.000 sebanyak 16 orang atau sebesar $20 \%$.

\section{Arah dan Arus Pelaku Mobilitas} Harian yang Keluar Kota Padang

Arah tujuan atau arus pergerakan penduduk harian keluar Kota Padang dapat dilihat pada tabel berikut ini:

Tabel 7: Arah dan Arus Pelaku Mobilitas Harian

\begin{tabular}{|c|c|c|c|c|c|c|c|}
\hline \multirow[t]{2}{*}{ NO } & \multirow[t]{2}{*}{ Daerah Tujuan } & \multicolumn{2}{|c|}{ Bus } & \multicolumn{2}{|c|}{ Kereta Api } & \multicolumn{2}{|c|}{ Jumlah } \\
\hline & & f & $\%$ & f & $\%$ & & \\
\hline 1 & Kab. Padang Pariaman & & & & & \multirow[t]{11}{*}{ f } & \multirow[t]{11}{*}{$\%$} \\
\hline & Lubuk Alung & 11 & 14 & & & & \\
\hline & Pasar Usang & 2 & 3 & & & & \\
\hline & Sicincin & 3 & 4 & & & & \\
\hline & Palapa & 3 & 4 & & & & \\
\hline 2 & Kota Pariaman & 3 & 4 & 20 & 25 & & \\
\hline 3 & Bukittinggi & 11 & 14 & & & & \\
\hline 4 & Padang Panjang & 9 & 11 & & & & \\
\hline 5 & Payakumbuh & 6 & 7 & & & & \\
\hline 6 & Lubuk Basung & 5 & 6 & & & & \\
\hline 7 & Batusangkar & 7 & 8 & & & & \\
\hline & Jumlah Responden & 60 & 75 & 20 & 25 & 80 & 100 \\
\hline
\end{tabular}

Sumber: Pengolahan Data Primer 2017

Peta Arah dan Tujuan Pelaku

Mobilitas Harian Keluar Kota Padang

Lewat Jalur Utara:

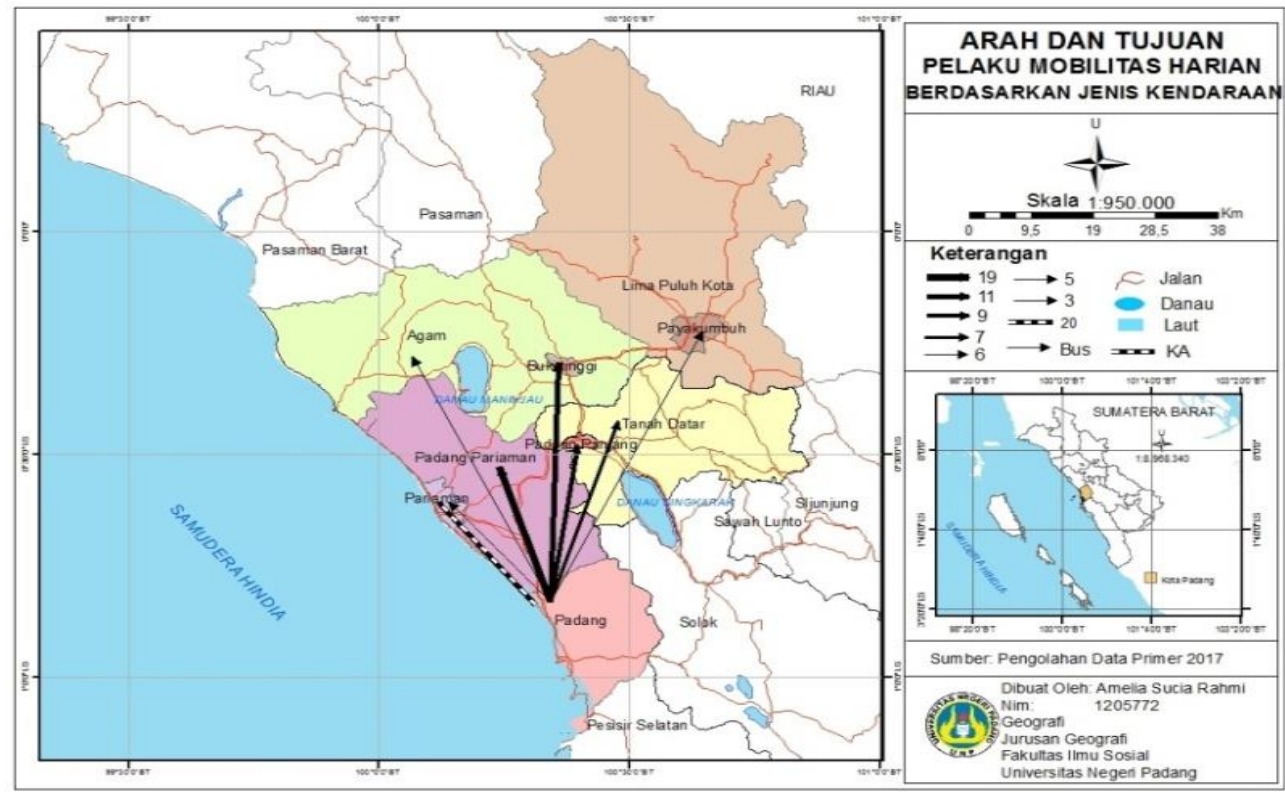

Berdasarkan tabel dan peta di atas, dapat diketahui bahwa Kabupaten
Padang Pariaman merupakan daerah tujuan yang paling banyak dituju oleh 
pelaku mobilitas harian yang berasal dari Kota Padang yakni dengan jumlah pelaku mobilitas harian 19 orang responden. Lalu diikuti oleh Kota Bukittinggi, daerah tersebut merupakan daerah kedua yang paling banyak dituju oleh pelaku mobilitas harian dengan jumlah 11 orang responden. Kota Padang Panjang merupakan daerah ketiga yang banyak dijadikan daerah tujuan mobilitas harian yakni dengan jumlah 9 orang responden atau pelaku mobilitas harian.

Kota Batusangkar merupakan daerah selanjutnya yang dituju oleh pelaku mobilitas harian yakni sebanyak 7 orang responden, lalu diikuti oleh Kota Payakumbuh dengan jumlah responden 6 orang. Lubuk Basung merupakan daerah yang memiliki jumlah sebanyak 5 orang. Kota Pariaman merupakan daerah tujuan paling sedikit dituju dengan menggunakan bus, pelaku mobilitas harian lebih memilih menggunakan kereta api untuk menuju ke Kota Pariaman karena selain biaya transportasinya yang murah, dengan menggunakan kereta api pelaku mobilitas lebih cepat sampai ke daerah tujuan mobilitas harian.

\section{Kontribusi Mobilitas Harian terhadap Pendapatan Pelaku Mobilitas Harian}

Kontribusi mobilitas harian terhadap pendapatan pelaku dapat dilihat dari apakah pendapatan pelaku tersebut meningkat setelah melakukan mobilitas harian atau malah menurun setelah melakukan mobilitas harian.

Berdasarkan data primer yang didapat dari hasil wawancara dengan responden di lapangan, maka dapat di ketahui pendapatan pelaku mobilitas sebelum melakukan mobilitas harian dapat dilihat pada tabel di bawah ini:

Tabel 8: Pendapatan Pelaku Mobilitas Sebelum Melakukan Mobilitas Harian

\begin{tabular}{|l|l|c|r|}
\hline No. & Pendapatan (rupiah) & f & \multicolumn{1}{|c|}{} \\
\hline 1 & $<500.000$ & 10 & 12 \\
\hline 2 & $>500.000-1.000 .000$ & 40 & 50 \\
\hline 3 & $>1.000 .000$ & 30 & 38 \\
\hline \multicolumn{2}{|c|}{ Jumlah } & $\mathbf{8 0}$ & $\mathbf{1 0 0}$ \\
\hline
\end{tabular}

Sumber: Pengolahan data primer 2017

Berdasarkah tabel di atas dapat diketahui pendapatan pelaku mobilitas sebelum melakukan mobilitas harian keluar Kota Padang berkisar antara $<500.000$ - >1.000.000.

Selanjutnya pendapatan pelaku mobilitas harian setelah melakukan mobilitas harian dapat dilihat pada tabel di bawah ini:

Tabel 9: Pendapatan Pelaku Mobilitas Setelah Melakukan Mobilitas Harian

\begin{tabular}{|l|l|l|r|}
\hline No. & Pendapatan (rupiah) & \multicolumn{1}{|c|}{ f } & \multicolumn{1}{|c|}{} \\
\hline 1 & $1.500 .000-3.000 .000$ & 40 & 50 \\
\hline 2 & $3.100 .000-4.500 .000$ & 24 & 30 \\
\hline 3 & $4.600 .000-6.000 .000$ & 16 & 20 \\
\hline \multicolumn{2}{|c|}{ Jumlah } & $\mathbf{8 0}$ & $\mathbf{1 0 0}$ \\
\hline
\end{tabular}

Sumber: Pengolahan data primer 2017

Berdasarkah tabel di atas dapat diketahui pendapatan pelaku mobilitas sebelum melakukan mobilitas harian keluar Kota Padang berkisar antara Rp 1.500.000 - 6.000.000.

Berdasarkan data primer yang didapat dari hasil wawancara dengan responden di lapangan, maka didapatkan bahwa kontribusi mobilitas harian terhadap pendapatan pelaku dapat dilihat pada tabel di bawah ini: 
Tabel 10: Kontribusi Mobilitas Harian terhadap Pendapatan Pelaku Mobilitas Harian

\begin{tabular}{|c|c|c|c|c|c|c|c|}
\hline \multirow{2}{*}{$\begin{array}{c}\text { No } \\
\text {. }\end{array}$} & \multirow[t]{2}{*}{ Pendapatan } & \multicolumn{2}{|c|}{ Bus } & \multicolumn{2}{|c|}{ Kereta Api } & \multicolumn{2}{|c|}{ Jumlah } \\
\hline & & f & $\%$ & f & $\%$ & & \\
\hline 1 & Meningkat & 42 & 53 & 11 & 14 & \multirow[t]{3}{*}{ f } & \multirow[t]{3}{*}{$\%$} \\
\hline 2 & Tidak meningkat & 9 & 11 & 4 & 5 & & \\
\hline 3 & Biasa saja & 9 & 11 & 5 & 6 & & \\
\hline & Jumlah & 60 & 75 & 20 & 25 & 80 & 100 \\
\hline
\end{tabular}

Sumber: Pengolahan Data Primer 2017

Berdasarkan tabel di atas dapat diambil kesimpulan bahwa dari 80 pelaku mobilitas harian baik yang menggunakan bus ataupun kereta api, 66 orang menyatakan bahwa pendapatan mereka meningkat setelah melakukan mobilitas harian keluar Kota Padang, sedangkan pelaku mobilitas harian yang pendapatannya tidak meningkat setelah melakukan mobilitas harian memiliki jumlah yang hampir seimbang dengan pelaku mobilitas harian yang pendapatan mereka biasa saja (tidak naik/tidak turun) yaitu dengan jumlah masing-masing sebesar 13 atau $16 \%$ dan 14 orang atau dengan persentase sebesar $18 \%$.

\section{Alasan Pelaku Mobilitas}

\section{Melakukan Mobilitas Harian}

Alasan pelaku mobilitas harian yang tinggal di Kota Padang melakukan mobilitas harian keluar Kota Padang yaitu dapat dilihat pada tabel di bawah ini:

Tabel 11: Alasan Melakukan Mobilitas Harian

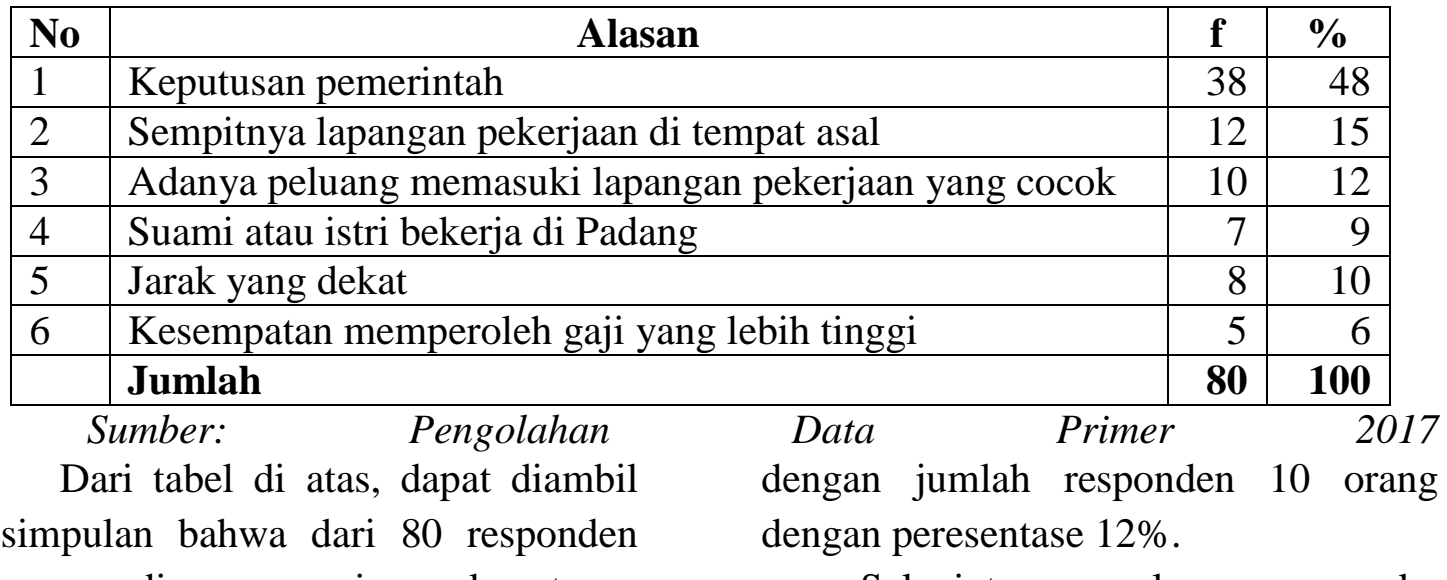

yang diwawancarai, keputusan pemerintah atau keputusan perusahaan merupakan alasan paling banyak dalam melakukan mobilitas harian keluar Kota Padang yakni sebanyak 38 orang atau $48 \%$. Diikuti alasan menyempitnya lapangan pekerjaan di tempat asal (Kota Padang) sebanyak 12 orang atau sebesar $15 \%$, alasan selanjutnya yaitu di daerah tujuan ada peluang pekerjaan
Selanjutnya alasan mereka melakukan mobilitas harian keluar Kota Padang dengan jumlah responden sebanyak 8 orang atau dengan persentase $10 \%$ adalah jarak yang tidak begitu jauh antara tempat tinggal dengan daerah tujuan, suami atau istri bekerja di Kota Padang merupakan alasan selanjutnya dengan jumlah 
responden sebanyak 7 orang atau persentase sebesar 9\%, kesempatan memperoleh pendapatan/gaji yang lebih tinggi memiliki jumlah sebanyak 5 orang atau dengan persentase sebesar $6 \%$.
Selanjutnya alasan pelaku mobilitas harian yang tinggal di Kota Padang melakukan mobilitas harian keluar Kota Padang dengan menggunakan angkutan umum bus dan kereta api dapat dilihat pada tabel di bawah ini:

Tabel 12: Alasan pelaku mbilitas harian menggunakan bus dan kereta api

\begin{tabular}{|c|c|c|c|c|c|c|c|}
\hline \multirow[t]{2}{*}{ No } & \multirow{2}{*}{ Alasan } & \multicolumn{2}{|c|}{ Bus } & \multicolumn{2}{|c|}{ KA } & \multirow{2}{*}{\multicolumn{2}{|c|}{ Jumlah }} \\
\hline & & $\mathbf{f}$ & $\%$ & $\mathbf{f}$ & $\%$ & & \\
\hline 1 & $\begin{array}{l}\text { Biaya transportasi yang cukup } \\
\text { murah dan lebih hemat }\end{array}$ & 24 & 30 & 6 & 7 & \multirow[t]{5}{*}{$\mathbf{f}$} & \multirow[t]{5}{*}{$\%$} \\
\hline 2 & $\begin{array}{l}\text { Bisa istirahat selama perjalanan dan } \\
\text { mengurangi resiko kecelakaan }\end{array}$ & 21 & 26 & 2 & 3 & & \\
\hline 3 & Tidak memiliki kendaraan pribadi & 7 & 9 & 3 & 4 & & \\
\hline 4 & Lebih cepat & 6 & 7 & 9 & 11 & & \\
\hline \multirow[t]{2}{*}{5} & $\begin{array}{l}\text { Ketersediaan angkutan umum yang } \\
\text { mudah didapat }\end{array}$ & 2 & 3 & - & - & & \\
\hline & Jumlah & 60 & 75 & 20 & 25 & 80 & 100 \\
\hline
\end{tabular}

Sumber: Pengolahan Data Primer 2017

Berdasarakan tabel di atas, dapat diambil kesimpulan bahwa ada beberapa alasan responden melakukan mobilitas harian keluar Kota Padang yang menggunakan angkutan umum bus, diantaranya biaya transportasi yang cukup murah dan lebih hemat dengan jumlah 30 orang atau sebesar $37 \%$.

Alasan selanjutnya adalah bisa istirahat selama perjalanan dan mengurangi resiko kecelakaan dengan jumlah responden sebanyak 23 orang atau sebesar $29 \%$, lalu diikuti dengan alasan tidak memiliki kendaraan pribadi dengan jumlah responden sebanyak 10 orang dengan persentase sebesar $12 \%$. Lebih cepat sampai di daerah tujuan merupakan alasan selanjutnya pelaku mobilitas lebih memilih menggunakan angkutan umum bus dengan jumlah 15 orang atau dengan persentase sebesar 19\%. Alasan terakhir adalah ketersediaan angkutan umum yang mudah didapat dengan jumlah responden sebanyak 2 orang atau dengan persentase sebesar $3 \%$.

\section{PEMBAHASAN}

Pertama, karakteristik pelaku mobilitas harian keluar Kota Padang yang melewati jalur utara yang menggunakan angkutan umum bus ataupun kereta api,dari jenis kelamin didominasi oleh perempuan dengan jumlah sebanyak 43 orang. Dari segi umur terdiri dari umur 21 - 62 tahun. Usia tersebut merupakan usia produktif, yang mana pada usia tersebut mereka masih mampu bekerja atau mempunyai tenaga lebih untuk bekerja dan menghasilkan sesuatu seperti uang atau upah. Status perkawinan didominasi yang bestatus sudah menikah. Tingkat pendidikan pelaku mobilitas harian terdiri dari pendidikan akhir SMP, SMA 
D3, S1, dan S2. Pelaku mobilitas harian yang pendidikan akhirnya S1 memiliki jumlah paling banyak yaitu sebanyak 47 orang, dan D3 memiliki jumlah paling sedikit dengan jumlah 4 orang. Jenis pekerjaan yang paling dominan adalah guru dengan jumlah 23 orang responden, sedangkan yang paling sedikit adalah wiraswasta dengan jumlah 5 orang responden. Pendapatan antara Rp 1.500.000/bulan - Rp $6.000 .000 /$ bulan. Hal ini sesuai dengan pendapat Suasti (2013) yang mengungkapkan bahwa mobilitas non permanen terdiri dari kelompok umur antara 20 dan 40 tahun, disaat pelaku mobilitas memutuskan untuk mulai mobilitas atau pergi dari daerahnya mereka berumur rata-rata dibawah 30 tahun. Tingkat pendidikan mempunyai korelasi dengan pekerjaan, baik di daerah asal maupun di daerah tujuan. Dalam keadaan normal, makin tinggi pendidikan seseorang makin besar kemungkinannya untuk memperoleh kesempatan kerja.

Kedua, berdasarkan wawancara dengan pelaku mobilitas harian di lapangan, diketahui bahwa daerah tujuan mobilitas terbanyak adalah Kabupaten Padang Pariaman dan Kota Pariaman. Dan untuk daerah tujuan paling sedikit yaitu Lubuk Basung. Hal ini sesuai dengan pendapat Sri, Omas Bulan (2010: 134) migrasi ulang alik (commuter), yakni pergerakan penduduk dari satu kota ke kota lain untuk bekerja atau berdagang, tetapi pulang pada sore harinya. Pendapat lain yang mendukung hasil penelitian adalah hukum migrasi dari E.G Ravenstein pada buti kesatu yaitu migrasi dan jarak.
Migrasi cendrung menempuh jarak dekat, dan apabila daerah tujuan semakin jauh, frekuensi migran menuju ke daerah tersebut semakin kecil. Migran yang menempuh jarak jauh umumnya menuju ke pusat-pusat perdagangan dan industi yang penting.

Ketiga, kontribusi mobilitas harian terhadap pendapatan pelaku mobilitas adalah meningkatnya pendapatan pelaku mobilitas harian setelah melakukan mobilitas harian dibandingkan sebelum melakukan mobilitas harian keluar Kota Padang. Hal ini sesuai pendapat Lee (1966) dalam Mantra (2009: 186) bahwa motivasi seseorang untuk pindah adalah motif ekonomi. Motif tersebut berkembang karena adanya ketimpangn ekonomi antar daerah.

Keempat, alasan pelaku mobilitas melakukan mobilitas harian adalah menyempitnya lapangan pekerjaan di daerah asal, SK Kepegawaian di daerah tujuan (bagi PNS), jarak yang dekat, keluarga yang menetap di daerah asal, kesempatan memperoleh pendapatan yang lebih tinggi, dan adanya kesempatan untuk memasuki lapangan pekerjaan yang cocok dan pendidikan yang lebih baik. Ada juga beberapa alasan responden melakukan mobilitas harian menggunakan angkutan umum yakni ketersediaan angkutan umum yang mudah didapat, biaya angkutan yang cukup murah dan lebih hemat, bisa beristirahat selama perjalanan dan menghindari resiko kecelakaan, tidak memiliki kendaraan pribadi, dan dengan angkutan umum pelaku mobilitas dapat lebih cepat sampai ke daerah tujuan. Hal ini sesuai dengan pendapat hukum 
migrasi E.G. ravenstein pada butir keenam yaitu teknologi dan migrasi. Peningkatan sarana perhubungan, perkembangan industri, dan perdagangan menyebabkan frekuensi migrasi meningkat. Dan butir ketujuh yaitu motif ekonomi merupakan dorongan utama. Volume migrasi yang tinggi didorong oleh keinginan untuk memperbaiki kehidupannya dalam bidang ekonomi.

\section{PENUTUP}

\section{Kesimpulan}

1. Karakteristik pelaku mobilitas harian keluar Kota Padang yang melewati jalur utara yang terdiri dari: Jenis kelamin pelaku mobilitas harian didominasi oleh pelaku yang berjenis kelamin perempuan, dengan umur didominasi oleh pelaku mobilitas yang berumur 35-48 tahun. Status perkawinan didominasi oleh yang bestatus sudah menikah, tingkat pendidikan didominasi oleh lulusan sarjana atau S1. Jenis pekerjaan pelaku mobilitas harian yang paling dominan adalah guru, dan pendapatan yang dominan jumlahnya adalah sebesar $\mathrm{Rp}$ 1.500.000 - Rp 3.000.000 dengan jumlah 37 orang responden.

2. Kabupaten Padang Pariaman merupakan daerah tujuan yang paling banyak dituju dengan jumlah 19 orang. Dan untuk daerah paling sedikit yaitu Lubuk Basung dengan jumlah 5 orang.

3. Kontribusi mobilitas harian terhadap pendapatan pelaku mobilitas harian adalah meningkatnya pendapatan pelaku mobilitas harian.

4. Alasan pelaku mobilitas adalah sempitnya lapangan pekerjaan di daerah asal, SK pegawai (bagi PNS), jarak yang dekat, keluarga bekerja di Padang, memperoleh pendapatan yang lebih tinggi, dan jenis pekerjaan yang cocok. Alasan responden melakukan mobilitas harian menggunakan angkutan umum yakni ketersediaan angkutan umum yang mudah didapat, biaya angkutan yang cukup murah dan dan dapat menghemat biaya, bisa beristirahat selama perjalanan dan menghindari resiko kecelakaan, tidak memiliki kendaraan pribadi, dan dengan angkutan umum pelaku mobilitas dapat lebih cepat sampai ke daerah tujuan.

\section{Saran}

Berdasarkan hasil penelitian dan kesimpulan di atas, maka peneliti memberikan saran sebagai berikut:

1. Disarankan kepada peneliti agar melakukan penelitian lebih lanjut mengenai dampak sosial budaya dari penduduk pasca melakukan mobilitas harian.

2. Disarankan kepada pemerintah agar memberikan fasilitas transportasi aksesibilitas yang lebih bagus, nyaman, serta modern. 


\section{DAFTAR PUSTAKA}

E.G. Ravenstein. Hukum Migrasi. http://yogieblog.blogspot.co.id/2008/03/7tujuh-butirhukum-migrasi-dari.html diakses tanggal 22 November 2017.

Mantra, Ida Bagoes. 2009. Demografi Umum, edisi kedua. Yogyakarta: Pustaka Pelajar.

Martono, Nanang. 2010. Statistik Sosial Teori dan Aplikasi Program SPSS. Yogyakarta: Gaya Media.

Pabundu, Tika Moh. 2005. Metode Penelitian Geografi. Jakarta: Gramedia Pustaka Utama.

Peraturan Presiden Republik Indonesia No. 153 Tahun 2014 tentang Grand Design Pembangunan Kependudukan.

Suasti, Yurni. 2013. Demografi. Padang: UNP Press.

Sugiyono. 2012. Metode Penelitian Kuantitatif, Kualitatif dan R\&D. Bandung: Alfabeta.

Sri, Omas Bulan. 2010. Dasar-dasar Demografi Edisi 2. Jakarta: Salemba Empat.

Tarigan, Robinson. 2005. Perencanaan Pembangunan Wilayah, Edisi Revisi. Jakarta: Bumi Aksara. 